\title{
Development of 6 U CubeSat's Deployable Solar Panel with Burn Wire Triggering Holding and Release Mechanism
}

\author{
Tae-Yong Park $\mathbb{D}^{1},{ }^{1}$ Bong-Geon Chae, ${ }^{2}$ and Hyun-Ung Oh $\mathbb{D}^{1}$ \\ ${ }^{1}$ Space Technology Synthesis Laboratory, Department of Aerospace Engineering, Chosun University, Gwangju, Republic of Korea \\ ${ }^{2}$ Dream Space World Co., Ltd., 193, Munji-ro, Yuseong-gu, Daejeon, Republic of Korea \\ Correspondence should be addressed to Hyun-Ung Oh; ohu129@chosun.ac.kr
}

Received 1 December 2018; Revised 15 February 2019; Accepted 26 February 2019; Published 30 April 2019

Academic Editor: Franco Bernelli-Zazzera

Copyright (C) 2019 Tae-Yong Park et al. This is an open access article distributed under the Creative Commons Attribution License, which permits unrestricted use, distribution, and reproduction in any medium, provided the original work is properly cited.

In the present work, a deployable solar panel based on a burn wire triggering holding and release mechanism was developed for use of $6 \mathrm{U}$ CubeSat. The holding and release mechanism was designed based on a nichrome burn wire cutting method widely used for CubeSat applications. However, it provides a high loading capability, reliable wire cutting, multiplane constraints, and handling simplicity during the tightening process of wire. A demonstration model of a printed circuit board-based solar panel stiffened by a high-pressure fiberglass-laminated G10 material was fabricated and tested to validate the effectiveness of the design and functionality of the mechanism under various test conditions. The structural safety of the solar panel combined with the mechanism in a launch vibration environment was verified through sine and random vibration tests at qualification level.

\section{Introduction}

A cube satellite (CubeSat) is a type of cube-shaped pico-class miniaturized satellite with a volume of $10 \mathrm{~cm}^{3}$ and a mass less than $1.33 \mathrm{~kg}$ with respect to a standard size of one unit $(1 \mathrm{U})$ [1]. In recent years, advanced missions using $6 \mathrm{U}$ CubeSats have grown considerably in the areas of space science $[2,3]$, exploration $[4,5]$, and earth observation $[6,7]$, because satellites can be built to have a small size to reduce the large economic cost of construction and launch. For example, JAXA is currently developing an OMOTENASHI that is a nanoscale lunar lander to observe the radiation environment on the lunar surface [2]. The NASA Jet Propulsion Laboratory (JPL) has developed and launched two Mars-orbiting CubeSats for Mars Cube One (MarCO) for a real-time communication link between the InSight Mars lander and Earth [4]. The JPL has also developed a RainCube for Earth's climate observation using a Ka-band deployable parabolic mesh antenna in low Earth orbit with an altitude of $400 \mathrm{~km}$ [6]. In addition, the size of CubeSat platforms has recently been further increased to $12 \mathrm{U}$ or $27 \mathrm{U}$ for achieving more challenging and more sophisticated missions [8].
As the size of CubeSat increases from $1 \mathrm{U}$ to $6 \mathrm{U}$, one of the technical challenges in the construction of an advanced CubeSat is to achieve sufficient power generation in restricted volume and electrical budgets. One potential solution to the problem of limited electrical power may be the adoption of various types of deployable solar panel, stowed during launch and deployed in orbit. Thus, CubeSat vendors have recently produced various types of deployable solar panel that are mostly based on PCBs stiffened by aluminum or carbon fiber composite materials [9-11]. These deployable panels require a holding and release mechanism (HRM) that provides adequate strength and stiffness to survive in the launch environment and release functions to make possible the deployment of these appendages in orbit. Recently, various HRMs were developed for the separation of deployable appendages for CubeSat applications. A nichrome burn wire cutting method $[12,13]$ has been widely used for the release of mechanical constraints on the deployable appendages of CubeSat owing to its simplicity and low cost. The release of the mechanical constraint is achieved by cutting the nylon wire triggered by heating a nichrome wire or burn resistor. This method also can be easily used for holding and releasing deployable 


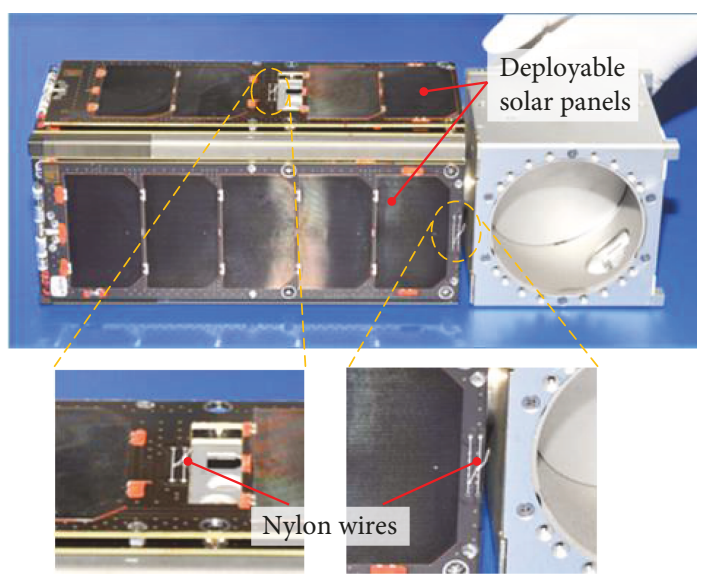

FIgURE 1: Example of conventional burn wire triggering type of HRM for 3 U CubeSat [14].

solar panels for use of CubeSat [9-11, 14]. As a representative example, Searles and Rockward [14] developed a burn wire-triggering type of mechanism for deployable solar panels for $3 \mathrm{U}$ CubeSats called MicroMAS. The solar panel is mechanically constrained by tightening the nylon wire through the mechanical hole interfaces on the solar panel, as shown in Figure 1. The nylon wire tightened on the solar panel is released by activation of a burn resistor or a burn wire. These mechanisms have proved their effectiveness for holding and releasing deployable solar panels for $1 \mathrm{U}$ - to 3 U-class CubeSats. However, these mechanisms should be improved to apply them for larger deployable solar panels of $6 \mathrm{U}$ or larger CubeSats because of their limited constraint capability, inability to constrain the in- and out-of-plane directions of a solar panel simultaneously, and difficult tightening process of the nylon wire on the flat surface of a solar panel. In addition, the tensioning applied to the nylon wire on the flat surface of a solar panel, as shown in Figure 1, might be easily loosened by the mechanical load on the solar panel in a launch environment because of the low tightening force and lack of constraint force implementation along the in-plane directions of a solar panel. Therefore, the conventional mechanisms might not be able to provide a sufficient constrain force to the deployable solar panels for $6 \mathrm{U}$ or larger CubeSats.

In addition, the increase in solar panel size would also lead to a larger dynamic deflection of the panel that causes delamination on solar cells with bonded junctions. The increased stiffness of the solar panel is one of the important factors for minimizing the deflection of the panel. This can be achieved by mounting additional stiffeners made out of aluminum or carbon fiber composite materials on the solar panel $[15,16]$, but increases the weight of the panel. The panel stiffness also can be easily increased by increasing the additional mechanical fixation points on the solar panel by applying multiple HRMs. However, if one of the mechanisms fails to release the launch constraint successfully, the solar panel cannot generate the expected power anymore, as the mission requires. In addition, when multiple HRMs are used, the available area to attach solar cells is also reduced because of the presence of a mounting interface for HRMs. Therefore, the minimization of the number of HRMs is an important task for the development of deployable solar panels for CubeSat applications. It also can lead to the enhancement of the power generation capability of solar panels and the weight reduction of the CubeSats with limited mass and volume.

To enhance the capability of the conventional burn wire release method, Park et al. [17] proposed a new version of a mechanism using a spring-loaded pogo pin developed for holding and releasing deployable solar panels for CubeSat applications. The outstanding features of the mechanism are a high loading capability in the in- and out-of-plane directions of solar panels, low shock level, synchronous release of multiple panels, and handling simplicity during the tightening process for the nylon wire. The feasibility of using pogo pins as a solar panel's release mechanism was successfully verified through validation tests. A unique solar panel deployment mechanism using shape memory alloy (SMA) for CubeSats was developed by Perez [18]. That work introduced the use of a NiTi-based SMA in conjunction with an $\mathrm{Al}$ bushing to create a holding and release function on the mechanism, which secures mechanical releases in a nonexplosive manner, increasing the probability of success while eliminating residual shock from deployment. Several types of the commercial nonexplosive SMA actuator [19, 20] have been developed and used in various space missions. However, although the commercial SMA mechanisms have many technical advantages and space heritages, the use of these devices is impractical for CubeSat applications because of their high cost, required power, and spatial constraints in the limited volume of the CubeSat.

Many mechanisms based on the wire cutting method for the purpose of use in CubeSat applications have also been developed that are not only dedicated to the solar panel release mechanism. To release the tether deployment system, a burn wire release mechanism utilizing a compression spring system to apply a force and stroke to the nichrome burn wire to ensure a safer release was developed, and their functional performance was validated under vacuum condition by Thurn et al. [12]. A segmented nut-type HRM with the advantages of a high load capacity and negligible shock was developed by $\mathrm{Oh}$ and Lee [21]. The nut segment constructed using a nylon wire winding is released by cutting the nylon wire by using the nichrome burn wire. The effectiveness of the design was verified through a functionality test and a static load test under qualification temperature limits on a demonstration model of the mechanism. Lee et al. [22] developed a new version of the hinge driving separation nut-type HRM, and it is simpler than that proposed in another research [21]. The mechanism was developed as a main payload for the STEP Cube Lab mission [23].

Considering the trend that the size of CubeSats has been increased, the development of more-reliable and simply applicable HRMs dedicated to larger deployable solar panels, such as for $6 \mathrm{U}, 12 \mathrm{U}$, and $27 \mathrm{U}$ CubeSats, could be needed in future CubeSat missions. This is the starting point of the present study. In this study, a new version of a burn wire triggering HRM for $6 \mathrm{U}$ solar panel application is proposed. It was investigated through function and launch vibration tests. 


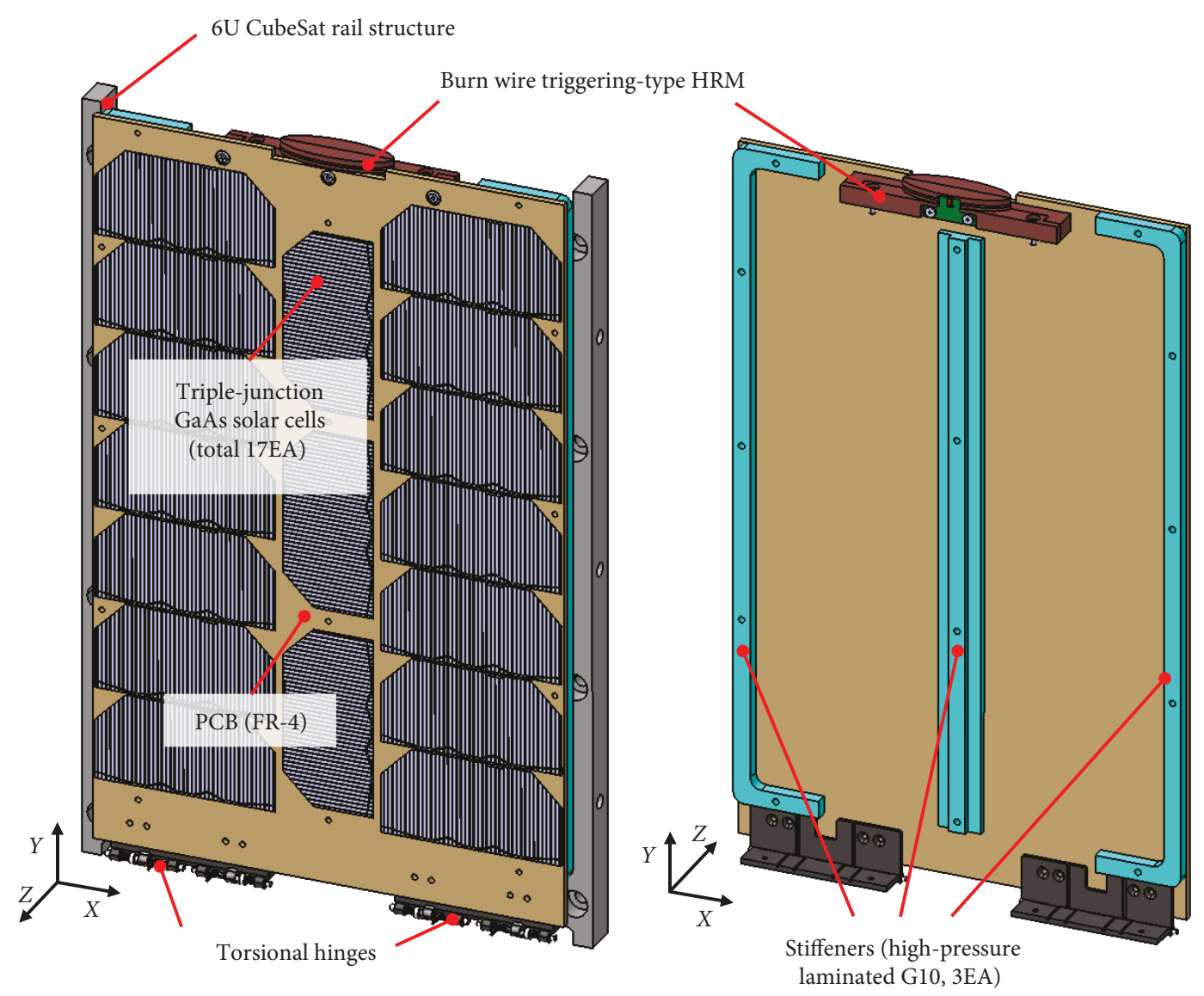

FIGURE 2: Overall configuration of $6 \mathrm{U}$ solar panel module with burn wire triggering type of HRM.

In this study, a printed circuit board- (PCB-) based solar panel stiffened by a high-pressure fiberglass-laminated G10 material was also verified in combination with the mechanism. The test results demonstrated that the mechanism provides advantages of a high loading capability, reliability, multiplane constraints, and handling simplicity during the tightening process of the wire.

\section{Design Description of a 6 U Solar Panel with Burn Wire Triggering HRM}

In this study, a $6 \mathrm{U}$ deployable solar panel with a burn wire triggering type of HRM, shown in Figure 2, is proposed. The deployable solar panel module is basically composed of a PCB panel with solar cells to generate power in-orbit, a burn wire triggering HRM to implement a holding and release function on the solar panel, stiffeners to increase the stiffness of the solar panel, and torsional hinges to provide torque for panel deployment. The PCB panel is made out of FR-4 material with dimensions of $209 \times 326.5 \times 3.35 \mathrm{~mm}$. Seventeen triple-junction GaAs solar cells with a conversion efficiency of $30 \%$ are attached on the front side of the PCB, so the expected power generation capacity of the solar panel is $19.5 \mathrm{~W}$. In the launch phase, the solar panel is stowed and constrained to the rail structure of the CubeSat by an HRM located at the PCB edge, as shown in Figure 2. However, in this condition, the dynamic deflection occurs mainly at the
PCB center, which means that the solar cells adjacent to this area are relatively vulnerable to delamination or fracture compared with the others located at the PCB edge. To ensure the structural safety of these solar cells in a severe launch environment, the stiffness of the PCB panel should be increased, because it is one of the important factors for minimizing deflection.

Therefore, in this research, stiffeners made out of highpressure laminated G10 material were considered in the design to increase the panel stiffness, as shown in Figure 2. To validate the effectiveness of the stiffener design, the first eigenfrequencies of stowed solar panels with and without the stiffeners were numerically analyzed under the assumption that the panel is rigidly constrained by the HRM. The results without stiffeners show that the first eigenfrequency of the solar panel was $70.5 \mathrm{~Hz}$. By applying stiffeners on the PCB panel, as shown in Figure 2, the first eigenfrequency could be increased to $130.9 \mathrm{~Hz}$, which is 1.86 times higher than that without stiffeners. These results indicate that the stiffener design proposed in this study is advantageous to guarantee the structural safety of the solar cells in accordance with the reduction of panel deflection. In addition, this design only requires a single HRM, such that the system is simpler and more reliable than the system with an increased number of fixation points on the solar panel by additional HRMs to increase the stiffness of the solar panel. The design using a single HRM also makes it possible to secure the 


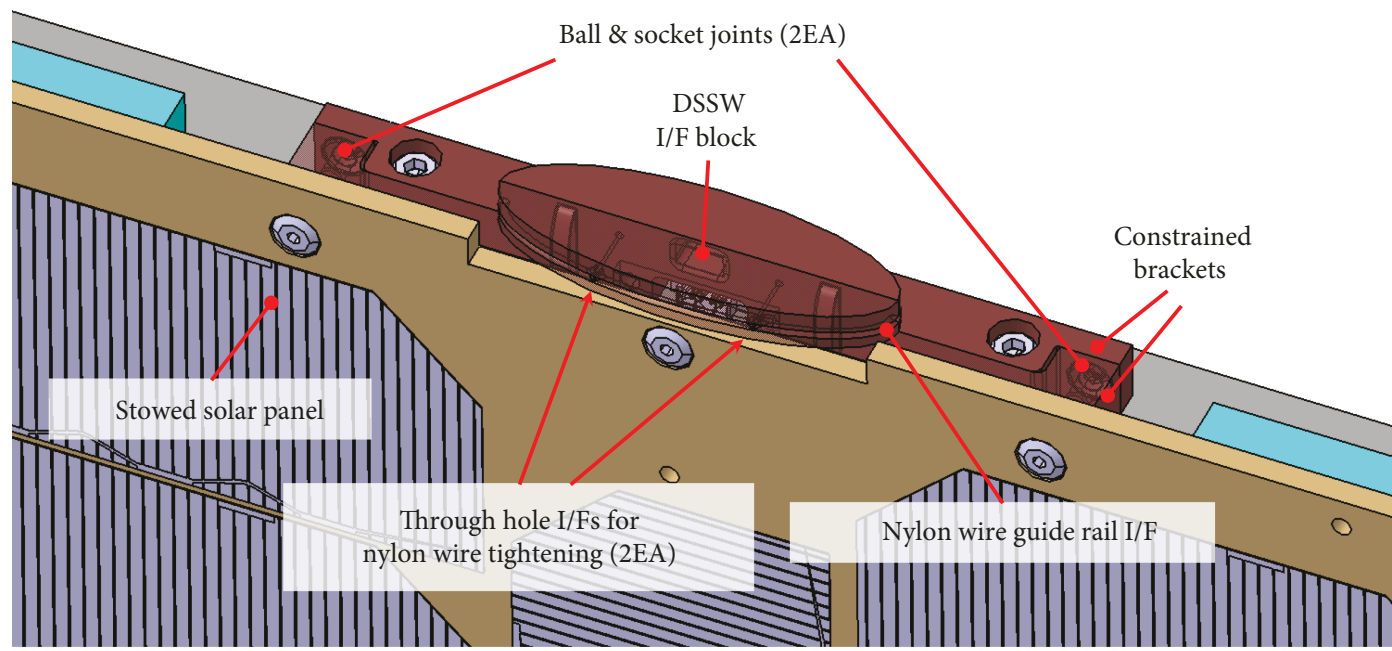

(a)

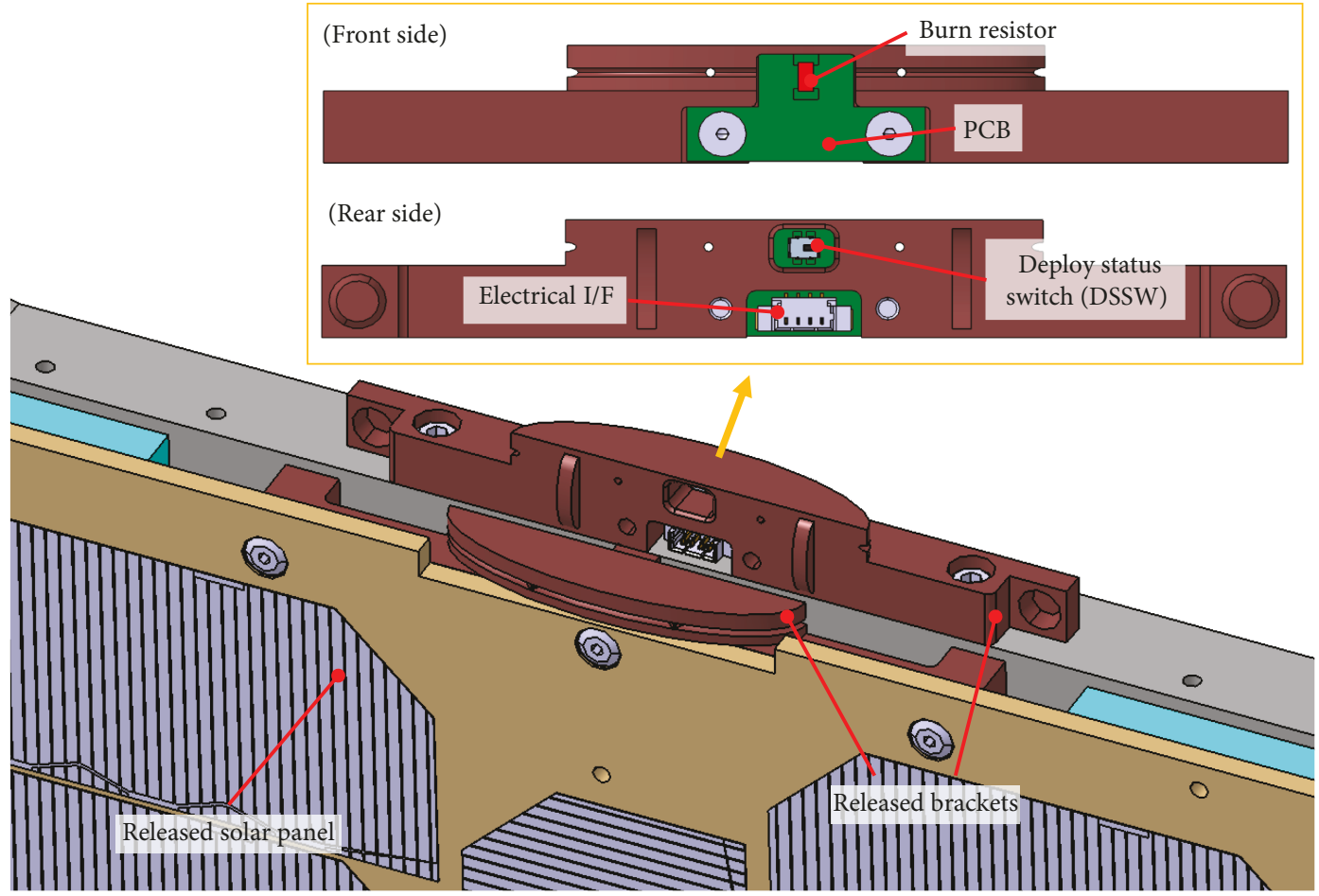

(b)

FIGURE 3: Close-up views of burn wire triggering type of HRM: (a) stowed configuration and (b) released configuration.

available area on the solar panel for solar cell accommodation, which enhances the power generation performance.

Figures 3(a) and 3(b) show close-up views of holding and released configurations of the solar panel module with the proposed burn wire triggering type of HRM, respectively. The HRM consists of two brackets, a PCB with a burn resistor and a deployment status switch (DSSW). The out-ofplane direction constraint of the solar panel is implemented by winding a nylon wire along the elliptical-shaped guide rail interface of the brackets installed on the solar panel and rail structure of the CubeSat, respectively. The in-plane directional constraint is achieved by a combination of ball-and- socket joints implemented on the brackets, as shown in Figure 3(a). The ability to constrain along multiplane directions of the solar panel proposed in this study is much more effective for safely holding the panel in a launch environment, in contrast to the conventional burn wire triggering type of mechanism that provides constraint along only the out-of-plane direction of the panel. The burn resistor soldered on the PCB is used as an actuator to cut the nylon wire tightened along the guide rail interface of the brackets. The PCB with a burn resistor is integrated with a bracket mounted on the CubeSat rail structure. To secure the contact between the burn resistor and nylon wire, the position of the 


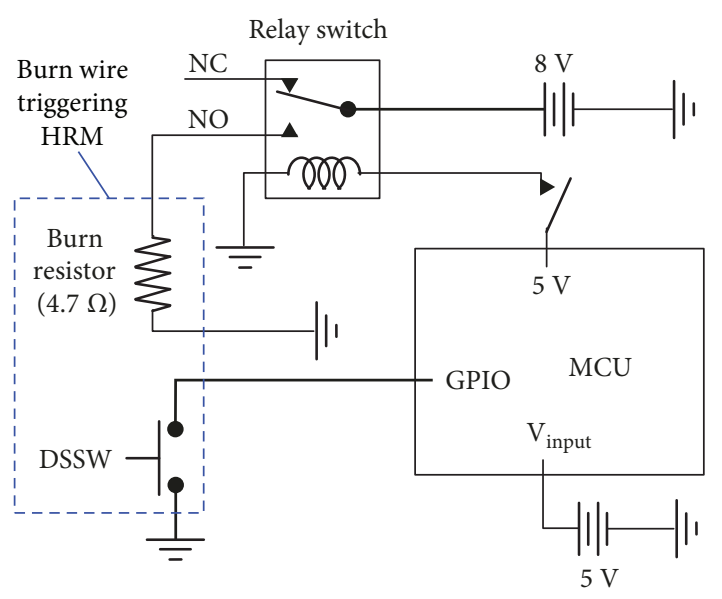

FIGURE 4: Electrical diagram of power cut off circuit for burn resistor.
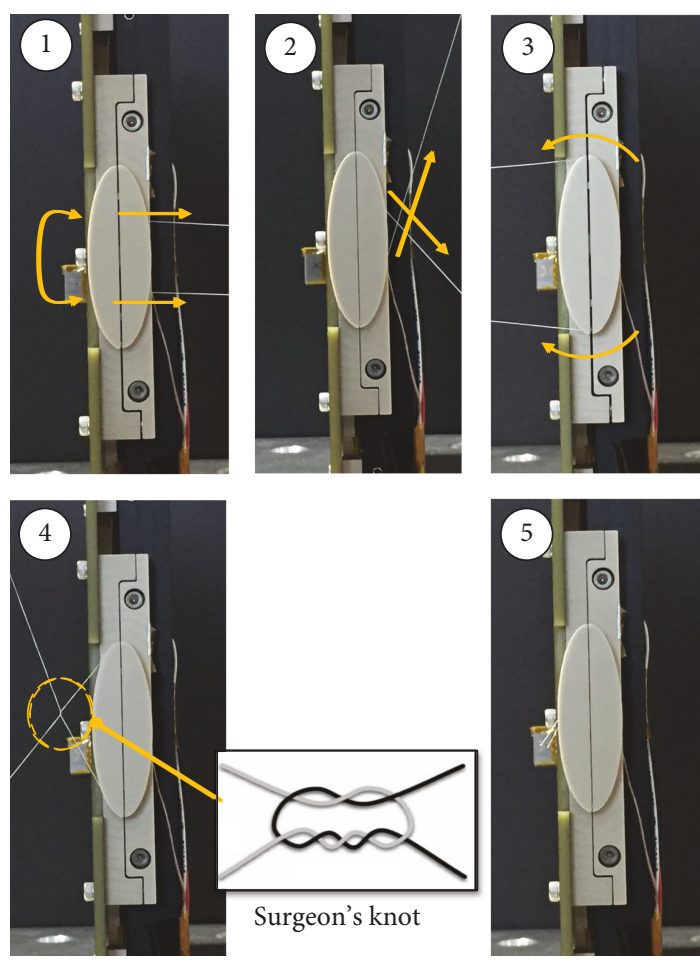

FIGURE 5: Optimized tightening process of nylon wire.

resistor is slightly higher than the surface of the guide rail interface for nylon wire tightening. This guarantees a more reliable cut through the nylon wire. The DSSW to judge the successful deployment of the solar panel is mounted on the rear side of the PCB. The electrical connector to supply power for the burn resistor and to receive the DSSW signal is also mounted on the same side of the PCB. After successful separation of the mechanism, the input power should be immediately cut off to prevent failure of the resistor due to overheating caused by the continuous power supply. This is important for determining the available number of mechanism activations, because frequent separation tests of the
TABLE 1: Specifications of the nylon wire and burn resistor.

\begin{tabular}{lcc}
\hline Item & Details & Value \\
\hline \multirow{4}{*}{ Nylon wire } & Manufacturer & Berkley Co. \\
& Material & Fluorocarbon \\
& Diameter & $0.1 \mathrm{~mm}$ \\
& Maximum allowable force & $56.22 \mathrm{~N}$ \\
\hline \multirow{4}{*}{ Burn resistor } & Manufacturer & Walsin Technology Co. \\
& Packaging type & Surface mount device \\
& Package size code & 3216 \\
& Electrical resistance & $4.7 \Omega$ \\
& Resistance tolerance & $\pm 1 \%$ \\
& Max. power dissipation & $0.25 \mathrm{~W}\left(T_{\mathrm{amb}}=70^{\circ} \mathrm{C}\right)$ \\
\hline
\end{tabular}

TABLE 2: Mass budget of $6 \mathrm{U}$ solar panel module.

\begin{tabular}{lc}
\hline Item & Mass (g) \\
\hline PCB panel with solar cells & 450 \\
Stiffeners (3EA) & 110 \\
Torsional hinges (2EA) & 25 \\
Burn wire triggering HRM & 20 \\
Mechanical parts (screws and nuts) & 20 \\
Total & 625 \\
\hline
\end{tabular}

solar panel are required during the on-ground validation test process prior to the launch of the CubeSat. The power cutoff function is implemented through the electrical circuit shown in Figure 4. This circuit is mainly composed of a microcontroller, relay switch, and power supply. The power supply provides input voltages of 8 and $5 \mathrm{~V}$ to the burn resistor and the DSSW, respectively. The microcontroller commands the relay switch to automatically cut off the input power to the resistor once the deploy signal is transmitted from the DSSW to the microcontroller via an analog to digital converter port.

Figure 5 shows a tightening process of the nylon wire along the guide rail interface of the brackets. The effectiveness of the tightening process was validated through separation tests of the HRM. This process provides reliable cutting of the nylon wire and an increased constraint force as the nylon wire is tightened along the elliptical guide rail interface of the brackets. However, the handling of the nylon wire during the tightening process becomes considerably simpler and reliable compared with the conventional mechanisms in which the nylon wire is tightened on the flat surface of the solar panel, as shown in Figure 1, which have been widely used for CubeSat applications.

Table 1 lists the specifications of the nylon wire and burn resistor used in the mechanism. A fluorocarbon wire with a diameter of $0.1 \mathrm{~mm}$ and a maximum allowable force of $56.22 \mathrm{~N}$ was used. In addition, a surface mount device chip resistor with a resistance value of $4.7 \Omega$ was used as the burn resistor. Table 2 presents the mass budget of the solar panel module shown in Figure 2. The total mass of the solar panel module was $625 \mathrm{~g}$. 


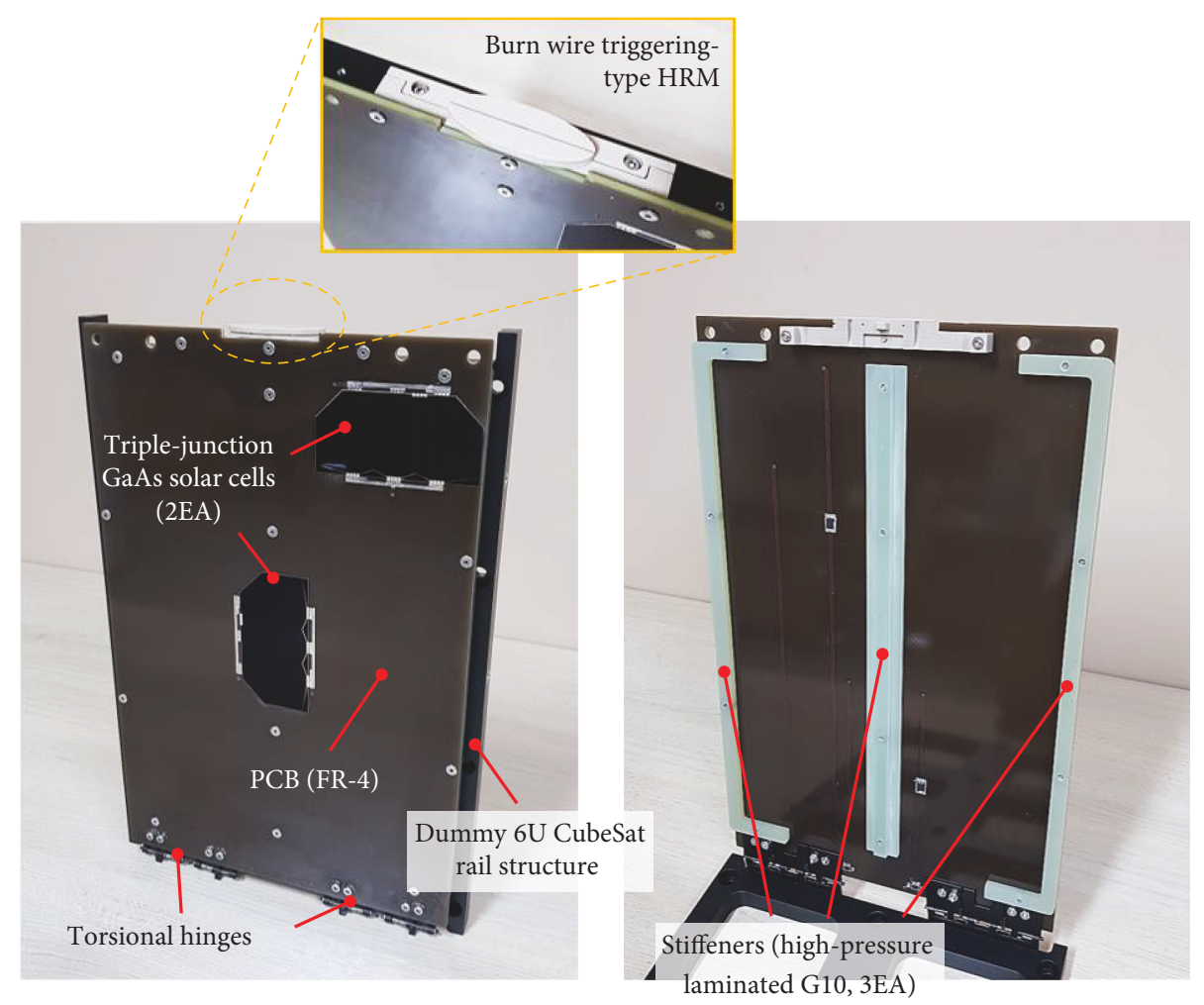

FIGURE 6: Demonstration model of 6 U solar panel module with HRM.

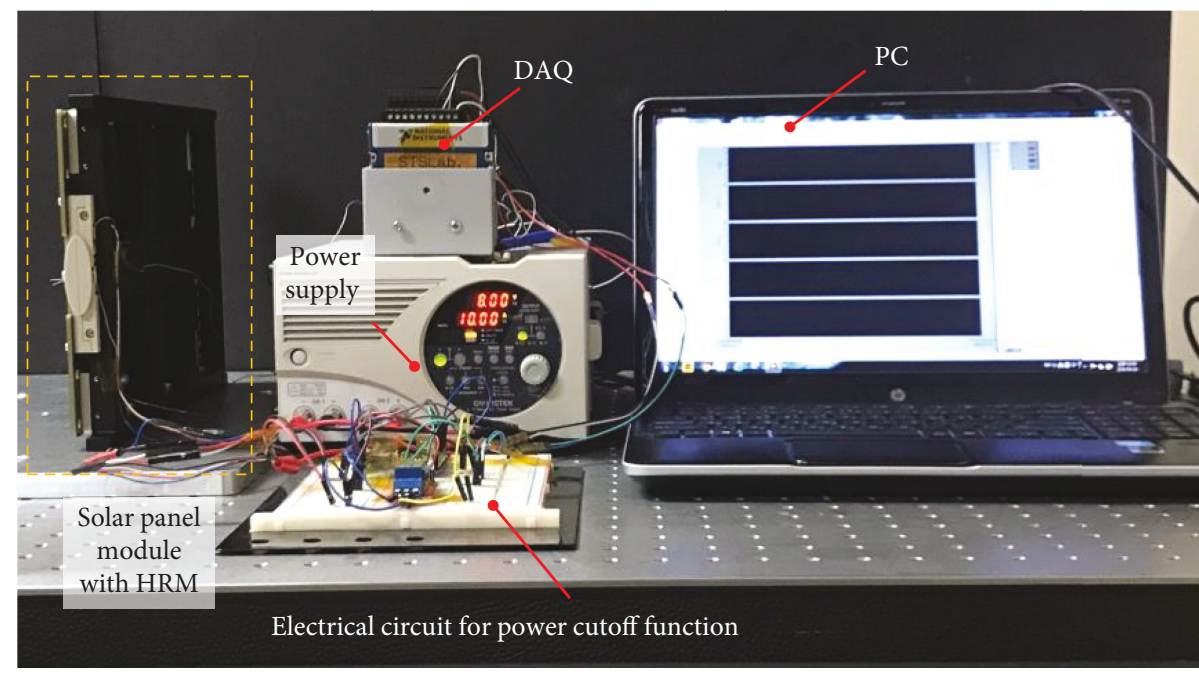

FiguRE 7: Release function test setup of the demonstration model of $6 \mathrm{U}$ solar panel module.

\section{Experimental Validation}

Figure 6 shows the development model of the $6 \mathrm{U}$ solar panel module with the burn wire triggering type of HRM to validate the effectiveness of the proposed design through release function tests and launch environment tests, such as sinusoidal vibration and random vibration tests. In the development model of the solar panel, two triple-junction GaAs solar cells (3G30A, AzurSpace Co.) were attached on the center and edge of the PCB panel, respectively, because the solar cells attached on those locations are vulnerable to fracture because of panel deflection under a launch vibration environment. The other parts, including the HRM proposed in this study, were the same as the configuration shown in Figure 2.

3.1. Release Function Tests. Figure 7 shows the release function test setup of the solar panel module to validate the stable release function of the mechanism. The test setup was mainly composed of a power supply to provide the input power to the mechanism, an electrical circuit to cut off the power immediately after release of the panel, as shown in Figure 4, and a data acquisition system to measure 

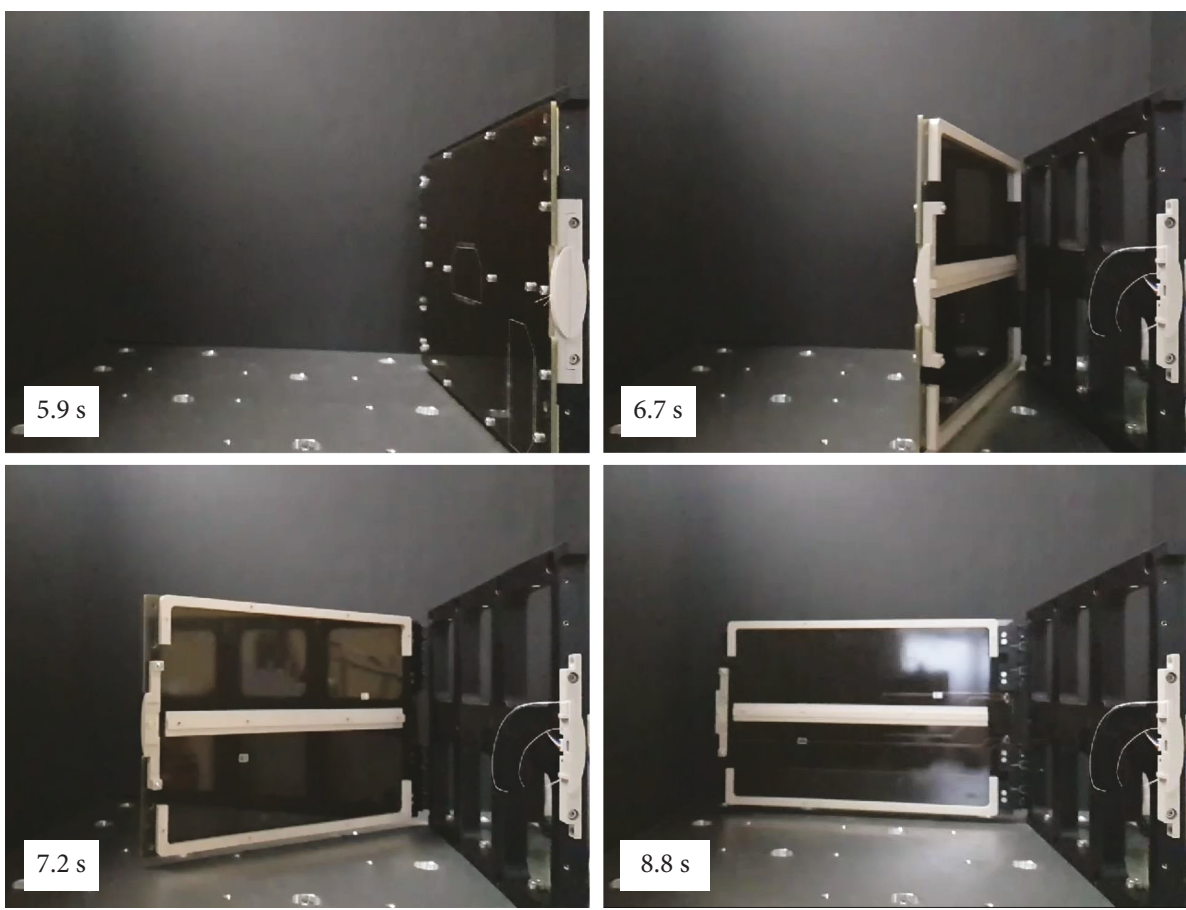

Figure 8: Sequential images of solar panel in deployment.

the input voltage and DSSW signal. In addition, an accelerometer was attached on the center of the panel to measure the acceleration during deployment. To monitor the temperature increase of the burn resistor during input voltage triggering to the mechanism, an infrared (IR) camera (FLIR T420) was used, although it is not shown in Figure 7 . The demonstration model of the solar panel was installed such that the rotational axis of the hinge was perpendicular to the test table for minimization of the effect of gravitational force during deployment. The input voltage to the resistor was set to $8 \mathrm{~V}$, which was determined through the preliminary tests. This was supplied by two onboard Li-ion battery cells connected in series. The release function tests were performed under various test conditions, such as differences in the number of wire windings, thickness of nylon wire, and temperature conditions.

Figure 8 shows the release function test results, i.e., sequential images captured by the high-speed camera during the deployment of solar panel. This test was performed at $20^{\circ} \mathrm{C}$ in an ambient environment. In the test, a mechanical constraint with one wire winding was implemented on the proposed mechanism. These results indicate that the deployment was successful without any mechanical interference. Figure 9 shows the time histories for the input voltage to the burn resistor, DSSW signal, and acceleration of the solar panel measured during the test. The release of the mechanical constraint of the solar panel was completed $0.53 \mathrm{~s}$ after the initiation of burn wire triggering, as shown in Figure 9. The full deployment of the solar panels took 2.83 s from completion of the release action.

Figure 10 shows the thermal images of the burn resistor captured by the IR camera during the release of the mechanism. After $0.58 \mathrm{~s}$ from the initiation of burn wire triggering

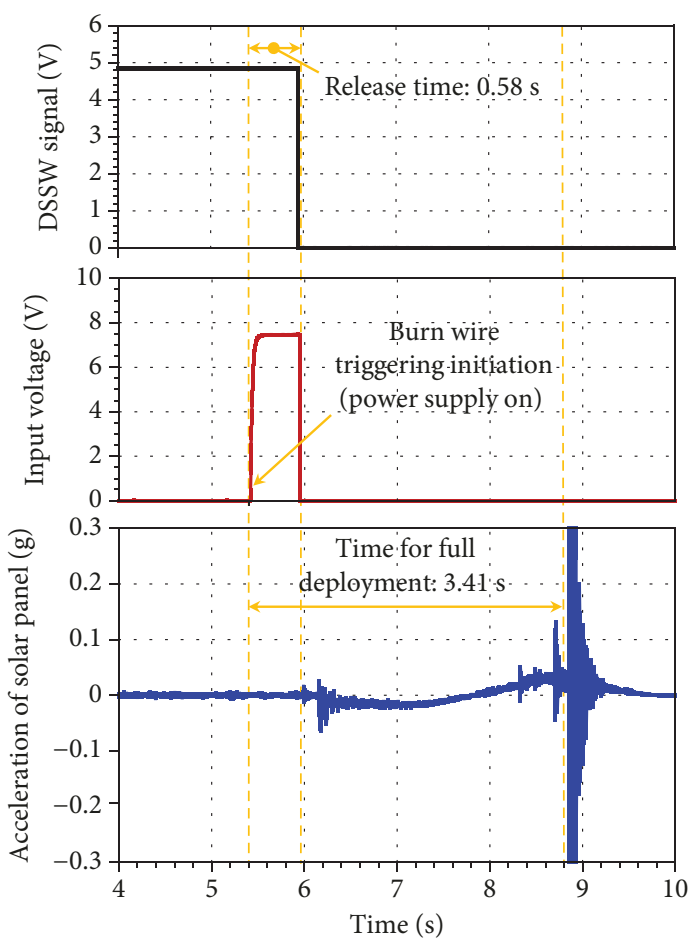

FIgURE 9: Time histories of DSSW signal, input voltage, and acceleration of solar panel during panel deployment.

at an ambient temperature of $20^{\circ} \mathrm{C}$, the temperature of the burn resistor reached approximately $150^{\circ} \mathrm{C}$, at which point the mechanical constraint was released. The temperature decreased immediately after the release action because of the automatic cutoff of input power to the resistor by the 

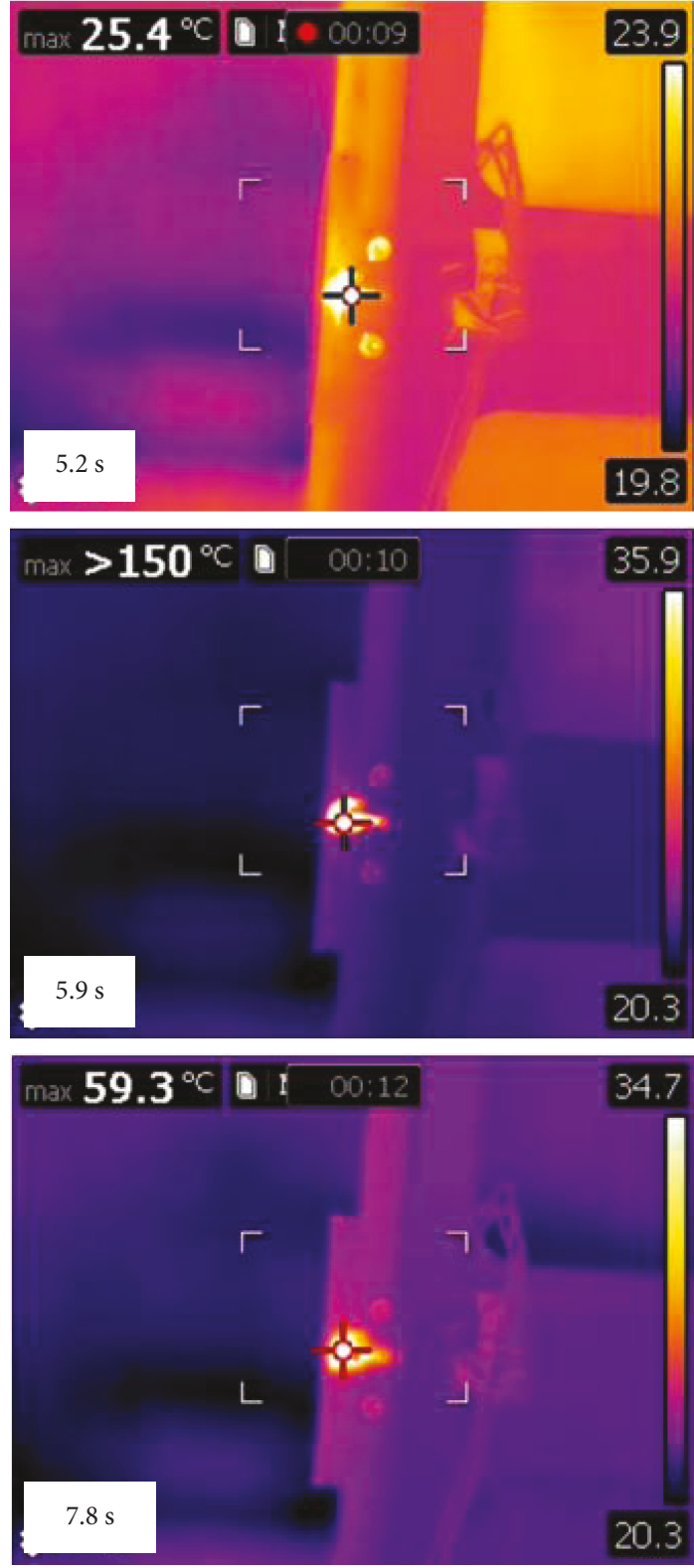

Figure 10: Thermal images of the burn resistor during HRM activation.

circuit shown in Figure 7. Therefore, this power cutoff function ensures the stable functioning of the mechanism during the repetitive release tests by preventing the overheating of the resistor.

Figure 11 shows the release times of the mechanism obtained during 30 repetitive function tests. The measured release times were less than $0.78 \mathrm{~s}$, although there were slight variations. These test results indicate that the proposed mechanism guarantees a reliable cut through the wire without performance degradation or failure of the burn resistor up to 30 activations of the mechanism. This ensures stable functioning of the mechanism during frequent on-ground separation tests prior to the actual flight demonstration.

For the burn wire triggering type of mechanism, the thickness of the nylon wire and the number of wire windings

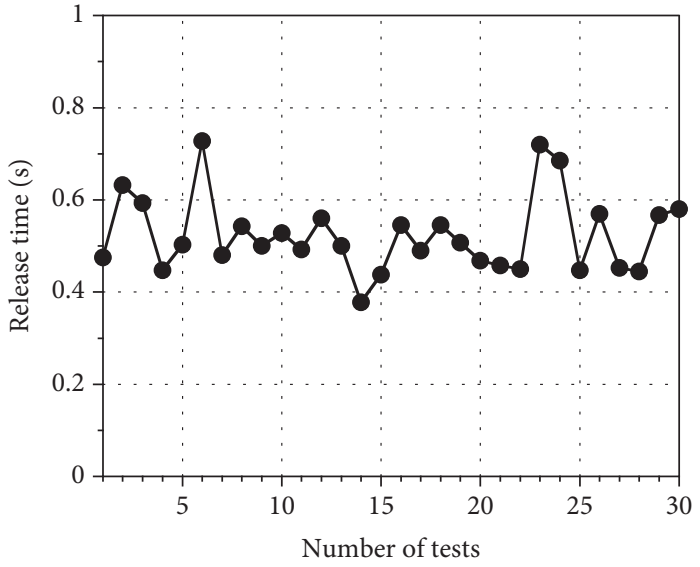

FIGURE 11: Release times of the solar panel during repetitive release function tests.

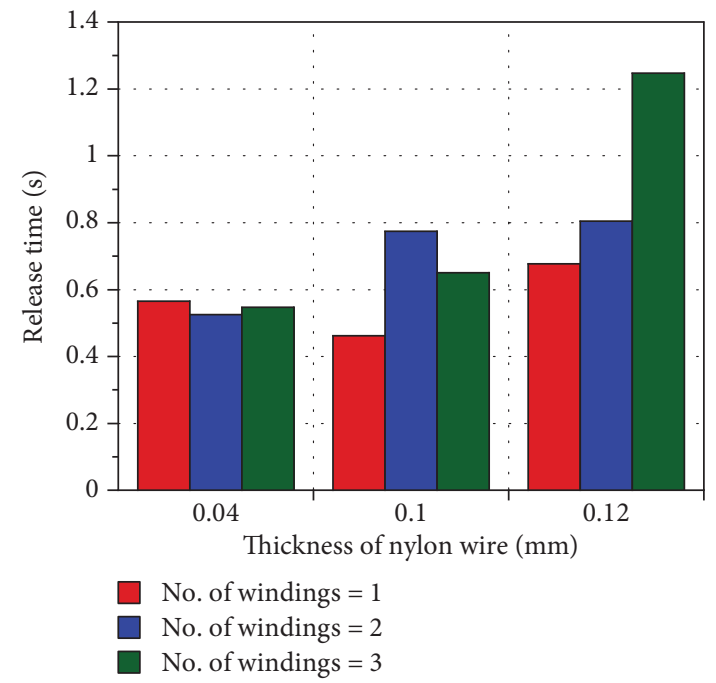

FIgURE 12: Release times of the solar panel as functions of the number of wire windings and thickness of nylon wire.

are key factors to ensure the mechanical constraint of the solar panel in a launch environment. However, these factors also affect the release function of the mechanism. Therefore, function tests with various thicknesses of the nylon wire and numbers of wire windings were performed, and the results are shown in Figure 12. These results indicate that the release time tends to increase when the numbers of wire windings and thicknesses of the wire increase. However, when one wire winding is applied to the mechanism, the results with $0.1 \mathrm{~mm}$ wire showed a $0.15 \mathrm{~s}$ shorter release time compared with that of $0.04 \mathrm{~mm}$ wire because of the irregular workmanship in applying the wire tightening force. The mechanism with triple windings of a nylon wire with $0.12 \mathrm{~mm}$ thickness showed a result of less than $1.25 \mathrm{~s}$ and guarantees a successful release of the solar panel.

To confirm the functional performance of the proposed mechanism under qualification temperatures ranging from $-35^{\circ} \mathrm{C}$ to $60^{\circ} \mathrm{C}$, function tests were performed with the same test setup as shown in Figure 7 . In the tests, the temperature reference point used to determine the stabilized target 


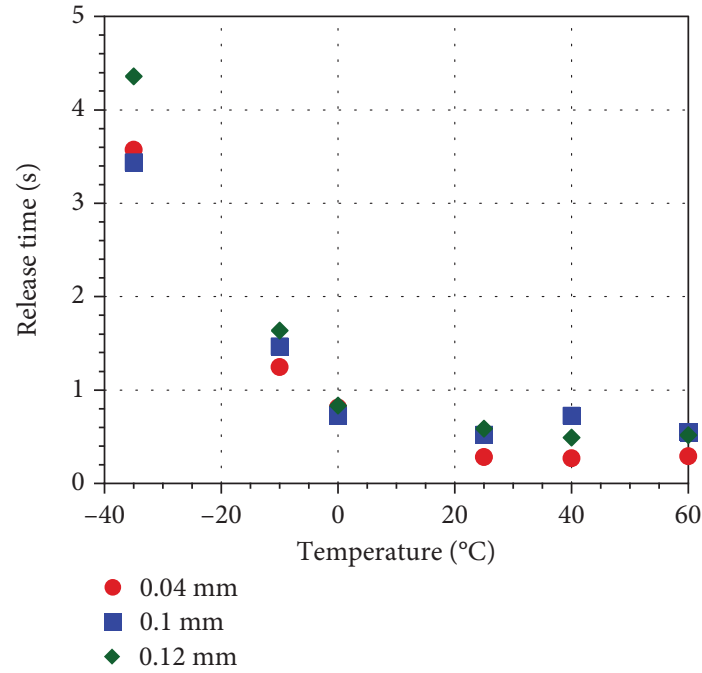

FIGURE 13: Release times of the solar panel as functions of thickness of nylon wire and qualification temperature ranges.

temperature is located at the $\mathrm{PCB}$ with a burn resistor. The tests were performed according to the various wire thicknesses when one wire winding was applied to the mechanism. The test results in Figure 13 show that the measured times to release the panel constraint were less than 0.38 and $0.6 \mathrm{~s}$ under low- and high-temperature conditions, respectively. These results indicate that the mechanism functions well under the qualification temperature limits, as intended in the design.

3.2. Launch Vibration Tests. To confirm the effectiveness of the proposed design of a solar panel module for the launch vibration environment, sine and random vibration tests were performed at qualification level. Figure 14 shows an example of the launch vibration test setup for the solar panel module for $z$-axis excitation of the solar panel. An accelerometer sensor to monitor the input test loads was mounted on the test jig. The acceleration responses of the solar panel were measured at the center of the panel. The qualification test specifications are summarized in Table 3 . The results of structural analysis prior to the launch vibration tests indicated that the predicted maximum force acting on the nylon wire was $57 \mathrm{~N}$ when the random qualification load was applied to the $z$-axis of the solar panel. This value exceeds the allowable force of the wire of $56.22 \mathrm{~N}$ shown in Table 1. Therefore, in the test, two cable windings were applied to the mechanism for the structural safety of the nylon wire under launch loads. Before and after each vibration test, the survivability of the solar cells was checked by an electroluminescence (EL) test for visual inspection of cracks in the solar cells and measuring the output voltages of the solar cells. In addition, the functionality of the mechanism was validated by the release function test after completing all the vibration tests.

Figure 15 shows an example of sine vibration test results for the solar panel module along the $z$-axis. In the test, a maximum input acceleration of $2.5 \mathrm{~g}$ was applied to the solar panel along each axis in the frequency range from 5 to $100 \mathrm{~Hz}$. The $z$-axis is the most critical axis because it has the largest dynamic deflection of the solar panel. A maximum acceleration response of $17.3 \mathrm{~g}$ was observed at a frequency of $78.4 \mathrm{~Hz}$. In addition, random vibration tests for each axis were performed in accordance with the test specifications listed in Table 3(b). Figure 16 shows the random vibration test result for the solar panel along the $z$-axis. The measured $G_{\text {rms }}$ value for the solar panel was 19.56 with respect to the test input of $14.1 G_{\mathrm{rms}}$. The maximum dynamic displacement of the solar panel, estimated from the three-sigma value of the $G_{\mathrm{rms}}$ response, was $2.38 \mathrm{~mm}$.

To verify the structural safety of the solar panel module, a modal survey test was performed before and after each vibration test. A sinusoidal vibration excitation with an amplitude of $0.1 \mathrm{~g}$ was applied to the solar panel module. Figure 17 shows the representative modal survey results of the acceleration response measured at the solar panel along $z$-axis excitation. The results obtained before the vibration tests indicate that the first eigenfrequency of the solar panel along the $z$ -axis was $78.6 \mathrm{~Hz}$, which is a 1.67 times lower value compared with the analysis results of $130.9 \mathrm{~Hz}$. This is because the mechanical constraint of the solar panel by the nylon wire was simply modeled using a rigid body element with a sixdegree-of-freedom constraint in the analysis, which provided a much stiffer constraint compared with the actual boundary condition fixed by the nylon wire.

To investigate the difference in first eigenfrequencies of the solar panel between the analysis and test, additional modal survey tests of solar panel were performed with rigid boundary conditions. In the tests, the hinges and mechanism located on the edges of the solar panel, as shown in Figure 6, were changed to bolted junctions to implement a rigid constraint condition on the panel. Figure 18 shows the acceleration responses obtained from the solar panel with bolted junctions during the modal survey tests along the $z$-axis. The results indicate that the first eigenfrequency of the solar panel became $140.9 \mathrm{~Hz}$, which was similar to the analysis results of $130.9 \mathrm{~Hz}$, although there was a difference of $7.6 \%$. In addition, it was approximately a two times higher value compared with the results of $69.5 \mathrm{~Hz}$ obtained from the panel with hinges and the mechanism shown in Figure 17. If only the hinges were changed to the bolted junctions, the frequency dropped to $89.5 \mathrm{~Hz}$, but it was still 1.3 times higher than the results with hinges and the mechanism. These observations indicate that the difference in the first eigenfrequency between the analysis and test is mainly caused by the decrease in stiffness provided by nylon wire tightening and the presence of backlash in the torsional hinges.

Table 4 summarizes the first eigenfrequencies of the solar panel obtained through the modal survey tests in each axis. The results indicate a frequency shift of $5.42 \%$ before and after the random test in the $z$-axis, which exceeds the requirement of the variation being within $5 \%$. However, the output voltage measurement results for the solar cells shown in Figure 19 indicate that both solar cells did not show any variation in voltage value before and after the vibration test, although there is a slight difference of $0.5 \%$. Thus, it was judged that the frequency shift did not affect the structural safety of the solar panel. This frequency shift phenomenon before and after vibration might be from the boundary 


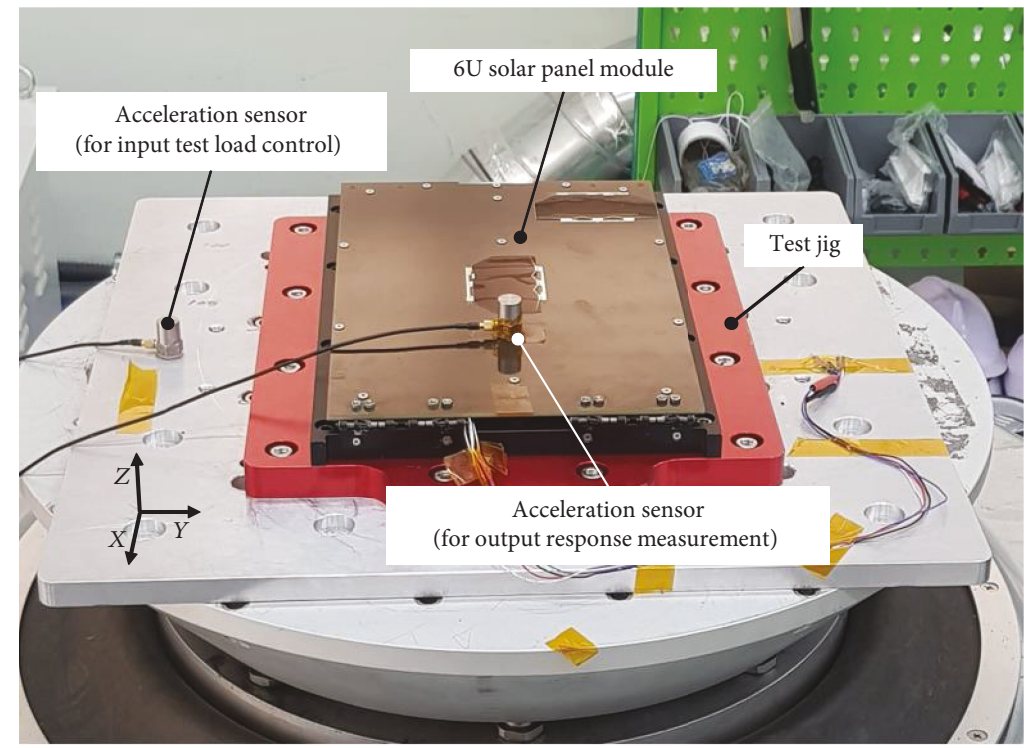

FIgURE 14: Launch vibration test setup of the demonstration model of the $6 \mathrm{U}$ solar panel module.

TABLE 3: Summary of qualification test specifications.

(a) Sinusoidal vibration test

\begin{tabular}{lcc}
\hline Frequency $(\mathrm{Hz})$ & Amplitude $(\mathrm{g})$ & Sweep rate $(\mathrm{oct} / \mathrm{min})$ \\
\hline 5 & 1.3 & \\
8 & 2.5 & 2 \\
100 & 2.5 & \\
\hline
\end{tabular}

(b) Random vibration test

\begin{tabular}{lccc}
\hline Frequency $(\mathrm{Hz})$ & Amplitude $(\mathrm{g})$ & Overall $G_{\mathrm{rms}}$ & $\begin{array}{c}\text { Test duration } \\
(\mathrm{min})\end{array}$ \\
\hline 20 & 0.026 & & \\
50 & 0.16 & 14.1 & 2 \\
800 & 0.16 & & \\
2000 & 0.026 & & \\
\hline
\end{tabular}

condition change of the solar panel caused by the backlash in the torsional hinges. In addition, a lower frequency for the deployable solar panel than the analysis result might be inevitable as long as the panel constraint is implemented by applying a single burn wire triggering mechanism and torsional hinges.

After completion of all the vibration tests, an EL test was performed to confirm the survivability of the solar cells. The principle of the EL test is based on an EL phenomenon in which light emission occurs when the electrical current flows through the photovoltaic solar cell. This phenomenon makes it possible to visualize the inherent defect and microcrack in the solar cell as a dark area. The EL test results shown in Figure 20 indicate no cracks or fractures on the tested solar cells. These test results indicate that the solar cells survived the vibration tests without any defects or performance degradation, although the first eigenfrequency of the solar panel was much lower than the expected value.

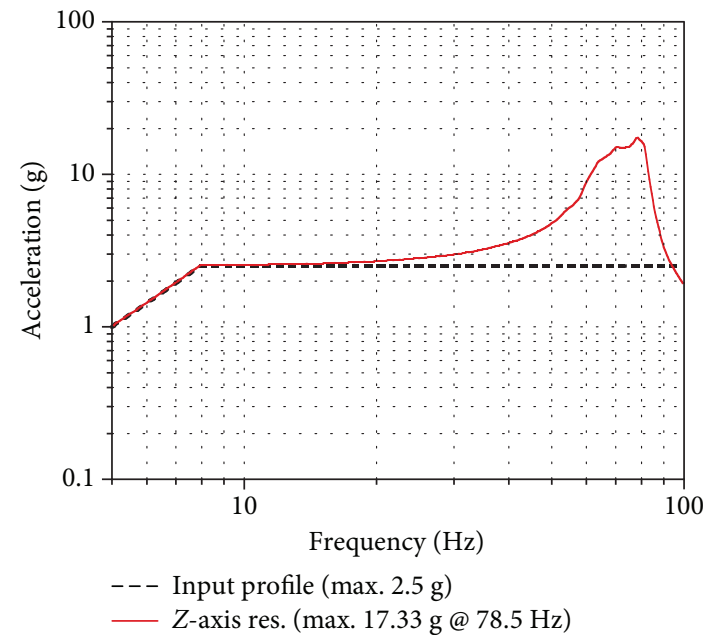

FIGURE 15: Sinusoidal vibration test results in the $z$-axis.

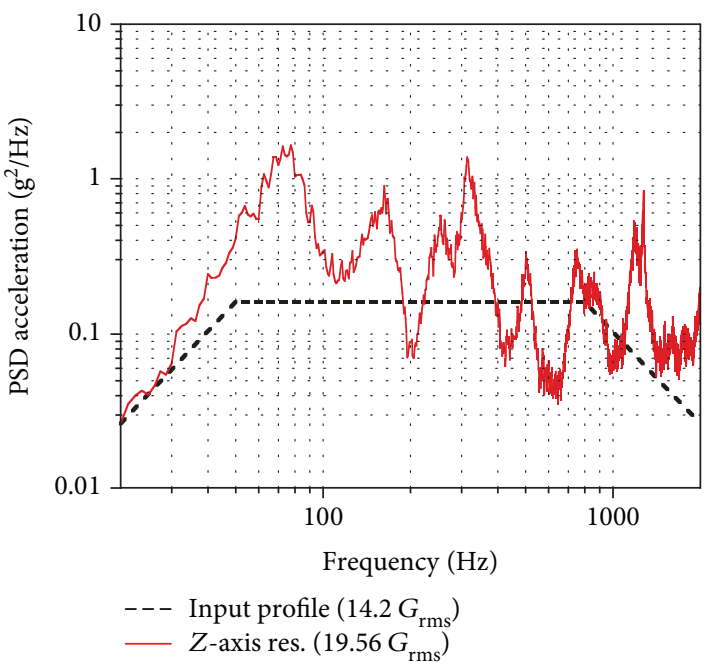

FIGURE 16: Random vibration test results in the $z$-axis. 


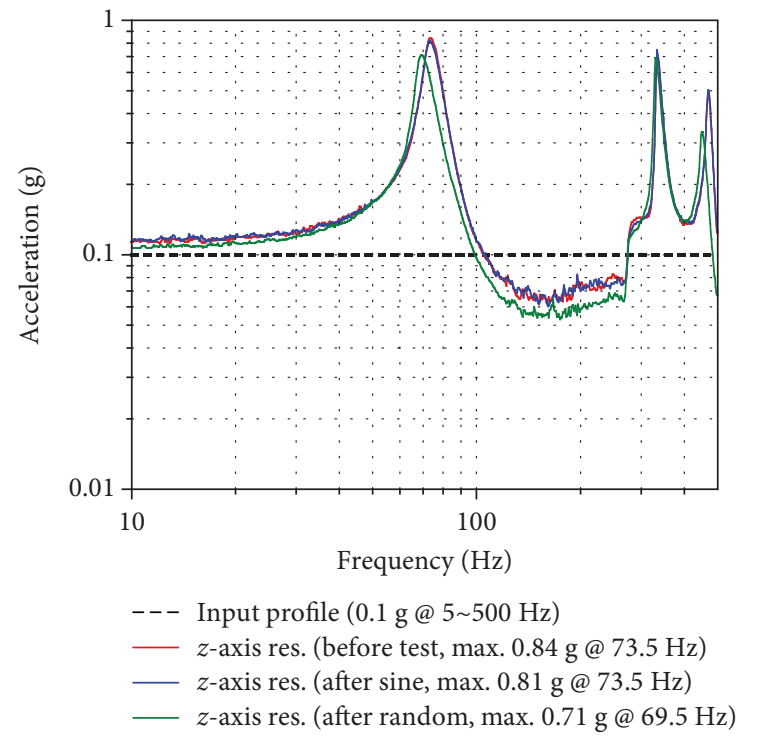

FIGURE 17: Low-level sine sweep results in the $z$-axis before and after launch vibration tests.

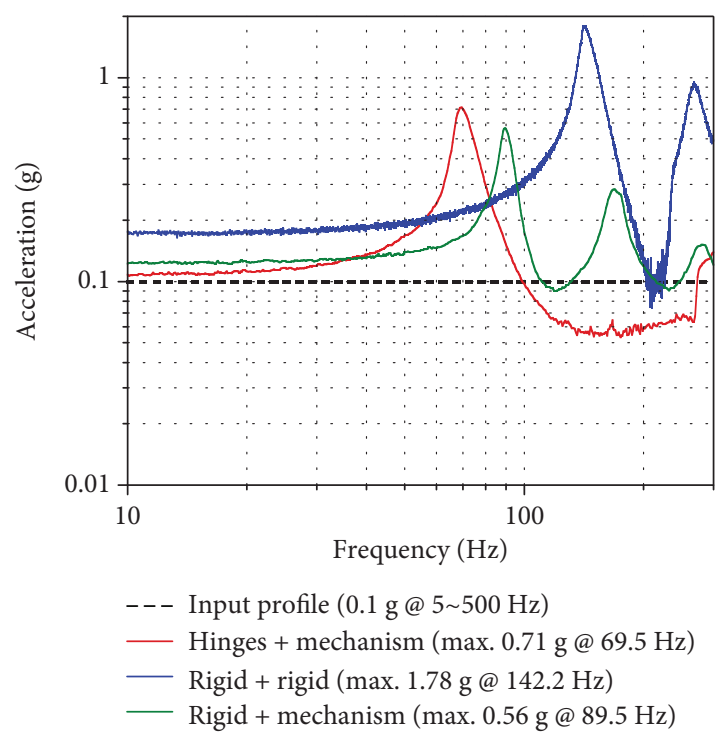

Figure 18: Low-level sine sweep results in the $z$-axis for the solar panel with rigid boundary conditions.

In addition, we also confirmed that the nylon wire tightened on the mechanism does not have any loosening or defects caused by friction between the wire and bracket or burn resistor due to the severe vibration excitation. Figure 21 shows the time history of the input voltage obtained during the release function test of the mechanism after completion of the vibration tests. For comparison, the results obtained before the vibration test are also plotted in the figure. The mechanical constraint of the mechanism was successfully released, and the release time was $0.61 \mathrm{~s}$, which had only a $15.1 \%$ difference from that measured before the vibration tests. The launch environment test results indicate that the proposed design of the solar panel module with a burn wire triggering HRM is effective for ensuring the structural safety of the solar panels in a launch environment.
TABLE 4: Low level sine sweep (LLSS) test results.

\begin{tabular}{lcccc}
\hline Test & & Axis & $\begin{array}{c}\text { 1st eigenfrequency } \\
(\mathrm{Hz})\end{array}$ & $\begin{array}{c}\text { Difference } \\
(\%)\end{array}$ \\
\hline \multirow{4}{*}{ Sine vibration } & $\mathrm{X}$ & Before & 324.06 & 0.68 \\
& & After & 326.26 & \\
& & Before & 378.9 & 0.32 \\
& & After & 381.27 & \\
& $\mathrm{Z}$ & Before & 73.41 & 0.23 \\
& & After & 73.24 & \\
Random & $\mathrm{X}$ & Before & 326.45 & 2.48 \\
vibration & & After & 318.35 & \\
& $\mathrm{Y}$ & Before & 377.8 & 0.73 \\
& & After & 380.54 & \\
& $\mathrm{Z}$ & Before & 73.24 & 5.42 \\
\hline
\end{tabular}

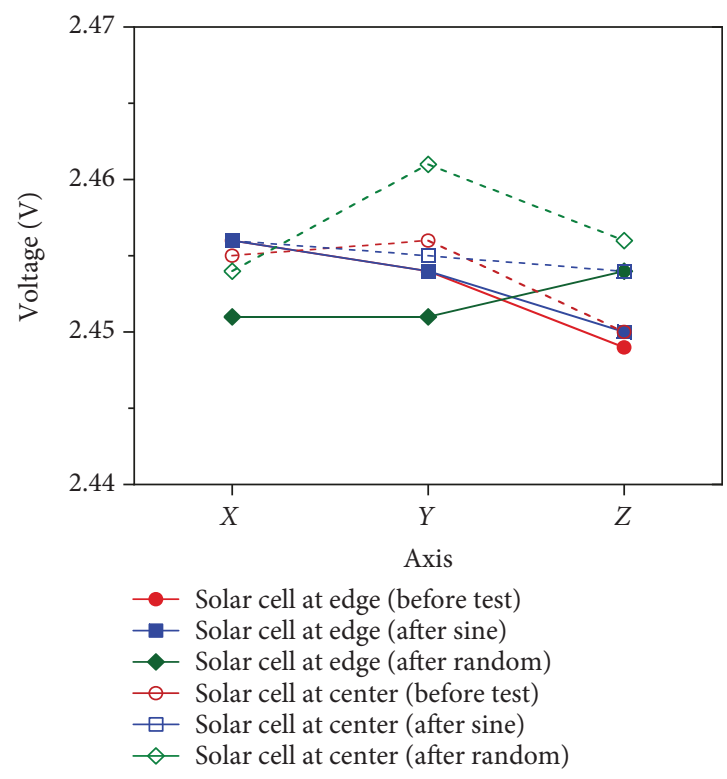

FIGURE 19: Measured output voltages of solar cells before and after launch vibration tests.

The $6 \mathrm{U}$ solar panel module with the mechanism proposed in this study has not yet been tested under a spacesimulated vacuum environment. However, all of the parts used in this study are capable of being used under extreme thermal vacuum conditions. In addition, the previous studies using similar burn wire release-type mechanisms demonstrated faster release times under vacuum conditions, compared with ambient conditions [22]. These observations will be confirmed in the near future through thermal vacuum testing of the flight model for the solar panel module with the mechanism.

In addition, although the functionality mechanism proposed in this study was successfully validated, the reliability of the DSSW used for the mechanism in this study might be insufficient to guarantee the reliability of the release function. Therefore, the flight model for the mechanism will reflect the shortest required power supply time, regardless 


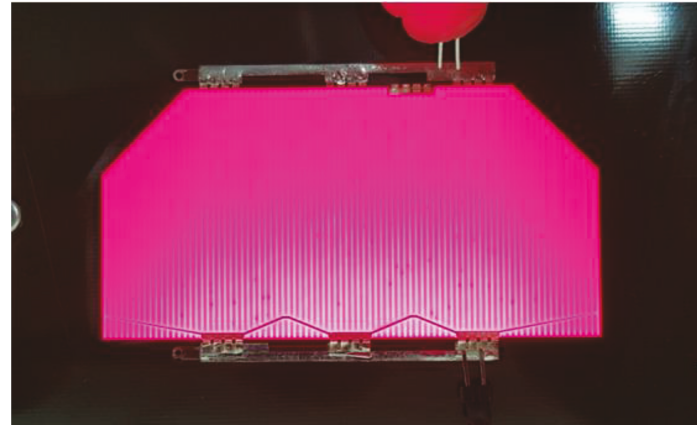

(a)

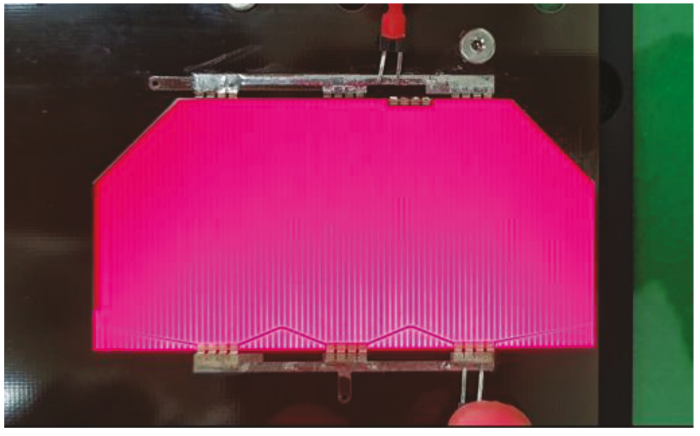

(b)

FIGURE 20: Electroluminescence (EL) test results of solar cells after launch vibration tests.

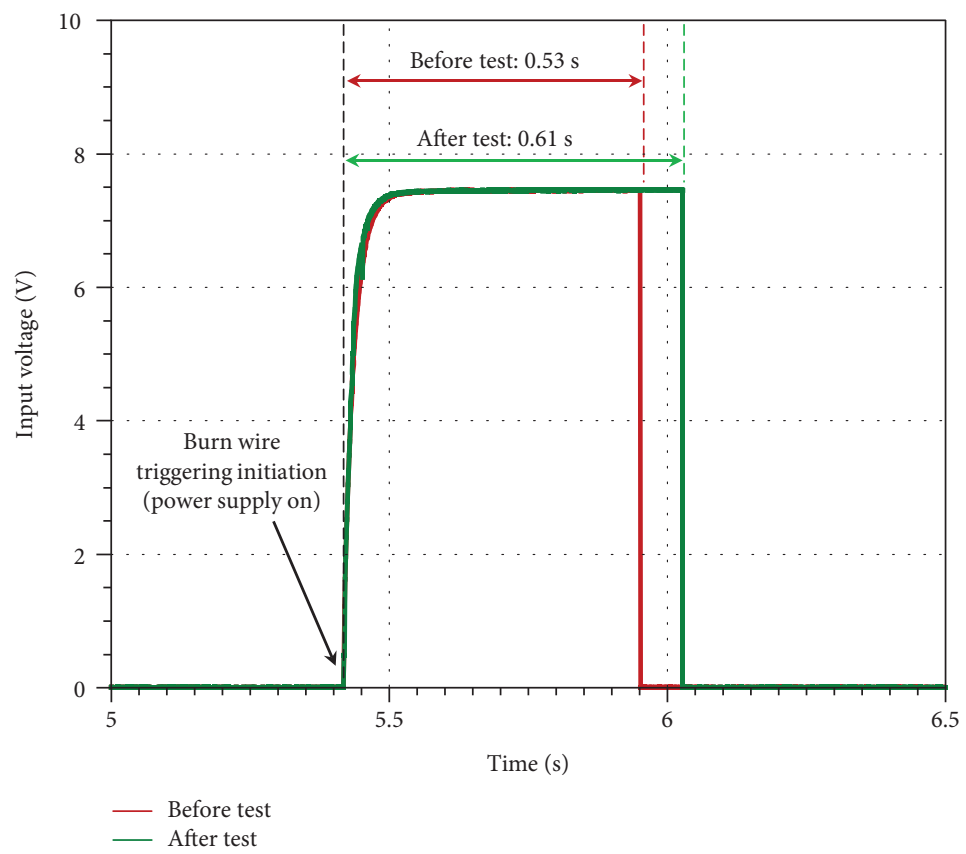

FIGURE 21: Time histories of release time of mechanism before and after launch vibration tests.

of the DSSW signal. This will prevent deployment failure caused by a malfunction of the DSSW.

\section{Conclusion}

In this study, a $6 \mathrm{U}$ CubeSat's solar panel module with a new version of a burn wire triggering type of HRM was proposed. The proposed solar panel module with stiffener design is advantageous to guarantee the structural safety of the solar cells in accordance with the reduction of panel deflection. This makes it possible to use only a single HRM for holding and releasing the mechanical constraint on the solar panel, which helps realize system simplicity and reliability owing to the minimization of the number of fixation points on the panel. In addition, the design also enhances the power generation capability of the solar panel by securing the available area on the solar panel for solar cell installation. The proposed mechanism in the study includes increased constraint capability along the multiplane directions of the solar panels and handling simplicity during the process of tightening the nylon wire. These advantages differentiate the proposed mechanism from the conventional ones based on a burn wire cutting method. To validate the effectiveness of the solar panel module design, release function tests were performed under various test conditions. In addition, the solar panel module was exposed to a launch vibration environment, and the survivability of the solar cells was validated by comparison of the output voltages measured before and after the vibration tests and the EL tests after completion of all the vibration tests. The test results indicate that the design approach proposed in this study is feasible for achieving the design objectives of the $6 \mathrm{U}$ solar panel module.

\section{Data Availability}

The data used to support the findings of this study are available from the corresponding author upon request. 


\section{Conflicts of Interest}

The authors declare that they have no conflicts of interest.

\section{Acknowledgments}

This research was supported by a research fund (2018) from Chosun University.

\section{References}

[1] K. Woellert, P. Ehrenfreund, A. J. Ricco, and H. Hertzfeld, "Cubesats: cost-effective science and technology platforms for emerging and developing nations," Advances in Space Research, vol. 47, no. 4, pp. 663-684, 2011.

[2] T. Hashimoto, T. Yamada, J. Kikuchi, M. Otsuki, T. Ikenaga, and OMOTENASHI Project Team, "Nano Moon Lander: OMOTENASHI," in Proceeding of 31st International Symposium on Space Technology and Science (ISTS), pp. 1-5, Matsuyama, Japan, 2017.

[3] NASA JPL, "Arcsecond Space Telescope Enabling Research in Astrophysics (ASTERIA)," 2016, http://www.jpl.nasa.gov/ cubesat/missions/asteria.php.

[4] J. Schoolcraft, A. T. Klesh, and T. Werne, "MarCO: Interplanetary Mission Development on a CubeSat Scale," in 14th International Conference on Space Operations (SpaceOps), pp. 1-8, Daejeon, Korea, May 2016.

[5] Q. Vinckier, K. Crabtree, C. G. Paine, P. O. Hayne, and G. R. Sellar, "Design and characterization of a low cost CubeSat multi-band optical receiver to map water ice on the lunar surface for the lunar flashlight mission," in Proceedings Volume 10403, Infrared Remote Sensing and Instrumentation XXV; 104030R, San Diego, CA, USA, August 2017.

[6] E. Peral, S. Tanelli, Z. Haddad, O. Sy, G. Stephens, and E. Im, "RainCube: a proposed constellation of precipitation profiling radars in CubeSat," in 2015 IEEE International Geoscience and Remote Sensing Symposium (IGARSS), pp. 1261-1264, Milan, Italy, July 2015.

[7] T. S. Pagano, D. Rider, J. Teixeira et al., "The CubeSat Infrared Atmospheric Sounder (CIRAS), Pathfinder for the Earth Observing Nanosatellite-Infrared (EON-IR)," in 30th AIAA/USU Conference on Small Satellites, SSC16-WK-32, pp. 1-8, Logan, UT, USA, August 2016.

[8] https://www.nanosats.eu/.

[9] NanoAvionics Co., https://n-avionics.com/.

[10] Gomspace Co., https://gomspace.com/home.aspx.

[11] Clydespace Co., https://www.clyde.space/.

[12] A. Thurn, S. Huynh, S. Koss et al., "A nichrome burn wire release mechanism for CubeSats," in The 41st Aerospace Mechanisms Symposium, Jet Propulsion Laboratory, pp. 479-488, Hilton Pasadena, CA, USA, May 2012.

[13] K. Nakaya, K. Konoue, H. Sawada et al., "Tokyo Tech Cubesat: CUTE-I-design \& development of flight model and future plan," in AIAA 21st International Communications Satellite Systems Conference and Exhibit, pp. 2003-2388, Yokohama, Japan, 2003.

[14] T. A. Searles and W. S. Rockward, "Microgravity test of nanosatellite release mechanisms," in NSBE Aerospace Systems Conference, pp. 1-4, Arlington, VA, USA, 2014.

[15] ISISpace Co., https://www.isispace.nl/.

[16] Blue Canyon Technologies Co., http://bluecanyontech.com/.
[17] T. Y. Park, S. H. Kim, H. Kim, and H. U. Oh, "Experimental investigation on the feasibility of using spring-loaded pogo pin as a holding and release mechanism for CubeSat's deployable solar panels," International Journal of Aerospace Engineering, vol. 2018, Article ID 4854656, 10 pages, 2018.

[18] A. O. Perez, "Development, integration, and testing of a nanosatellite coupling mechanism using shape memory alloy for an interference joint," Naval Postgraduate School, Thesis, 2012.

[19] TiNi Aerospace Inc., https://tiniaerospace.com/.

[20] Arquimea Ingeniería S.L.U., http://www.arquimea.com/.

[21] H. U. Oh and M. J. Lee, "Development of a non-explosive segmented nut-type holding and release mechanism for cube satellite applications," Transactions of the Japan Society for Aeronautical and Space Sciences, vol. 58, no. 1, pp. 1-6, 2015.

[22] M. J. Lee, Y. K. Lee, and H. U. Oh, "Performance evaluation of hinge driving separation nut-type holding and releasing mechanism triggered by nichrome burn wire," International Journal of Aeronautical and Space Sciences, vol. 16, no. 4, pp. 602-613, 2015.

[23] S. J. Kang and H. U. Oh, "On-orbit thermal design and validation of $1 \mathrm{U}$ standardized CubeSat of STEP Cube Lab," International Journal of Aerospace Engineering, vol. 2016, Article ID 4213189, 17 pages, 2016. 


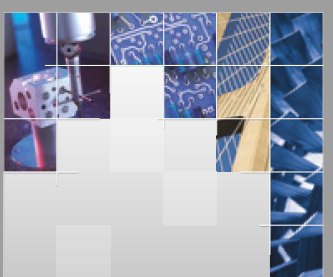

\section{Enfincering}
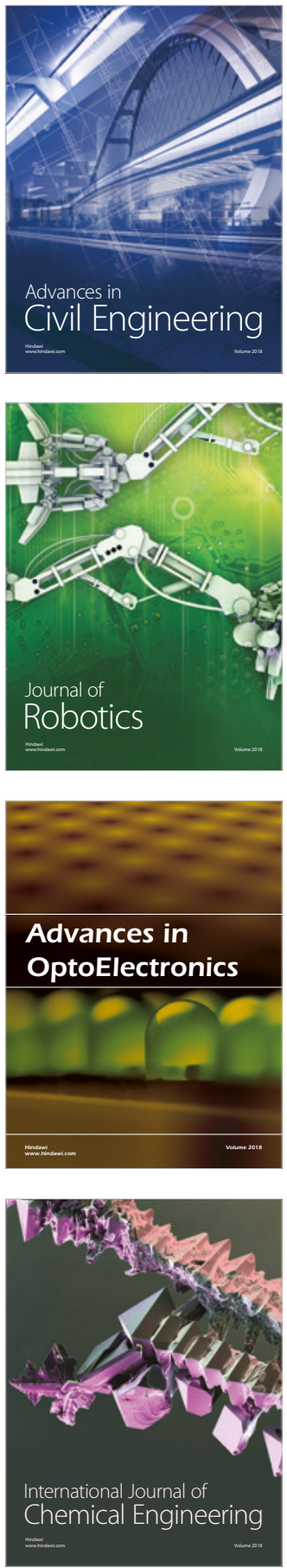

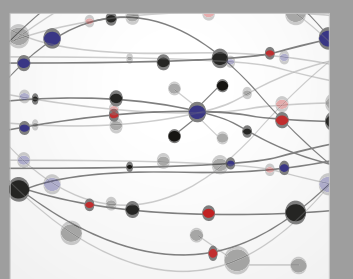

\section{Rotating \\ Machinery}

The Scientific World Journal

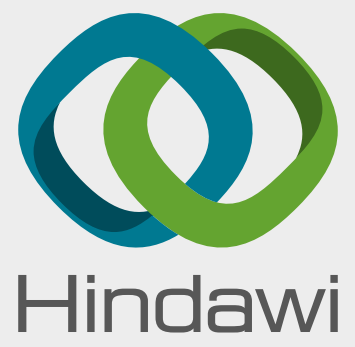

Submit your manuscripts at

www.hindawi.com
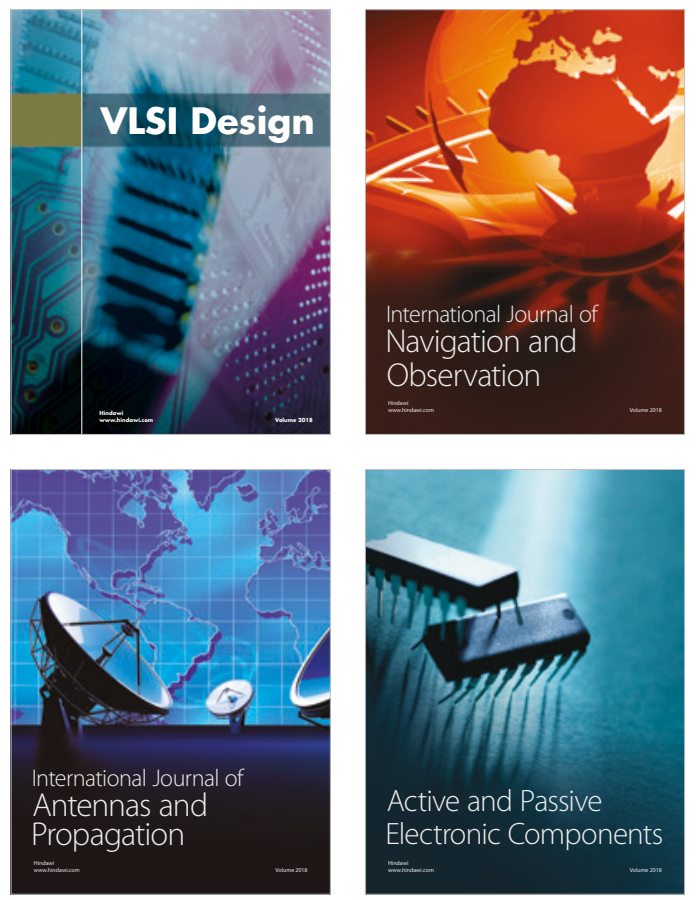
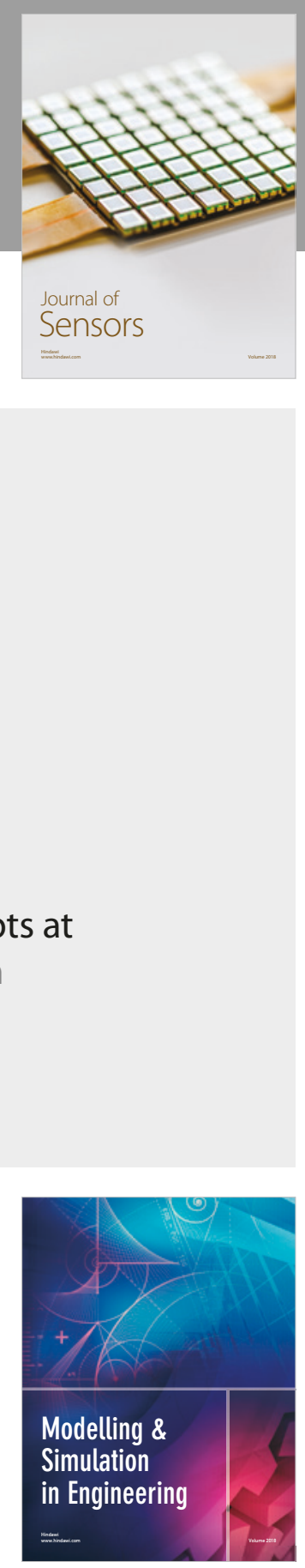

\section{Advances \\ Multimedia}
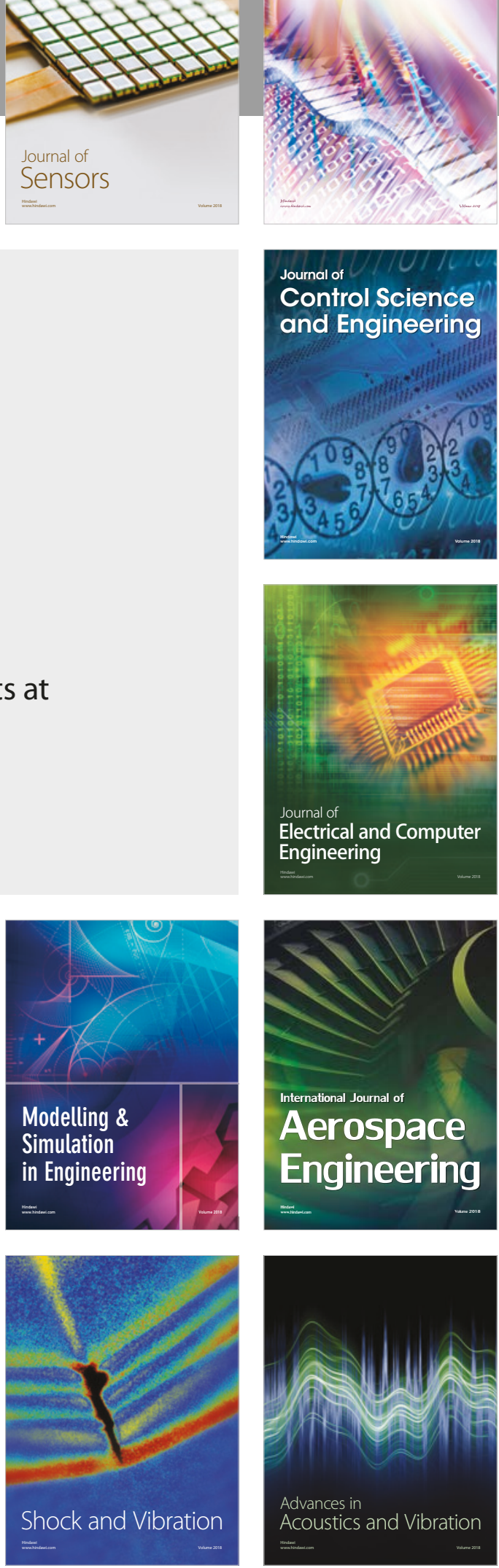